\title{
Asymmetric Analysis of Exchange Rates Volatility: Evidence from Emerging Economy
}

\author{
Atoi, N. Victor ${ }^{1} \&$ Nkwede E. Friday ${ }^{2}$ \\ ${ }^{1}$ Banking and Finance Department, Ebonyi State University, Abakaliki-Nigeria \\ ${ }^{2}$ Research and Statistic Department, Central Bank of Nigeria, Abuja-Nigeria
}

\begin{abstract}
The primary objective of this study is to empirically establish the level of volatility persistence and ascertain the presence of asymmetric effect on the three segment of the Nigerian foreign exchange market (Inter-bank Foreign Exchange Market (IFEM), bureau de change (BDC) and Wholesale Dutch Auction System (WDAS)). Asymmetric Threshold Generalized Authoregressive Conditional Heteroscadasticity (TGARCH) approach was adopted in the research methodology for the empirical analysis to capture the simultaneous estimation of the mean and the conditional variance in 1,262 sample observations. Generally, this study produced some interesting findings: first, it reveals that naira to US dollar nominal exchange rate volatilities were found to be persistent in all the market segments. Second, the exchange rate volatility in the interbank is persistent and explosive; while the volatilities in the BDC and WDAS market are high and moderate, respectively. This means that the BDC segment of the Nigerian foreign exchange market is less volatile than the interbank market segment even when the interbank segment of the market is more funded with foreign exchange from autonomous and official sources. Additionally, it is evident that interbank segment reacts more to past shocks of the foreign exchange market. Finally, the study also confirms the existence of asymmetric effect in the Nigerian foreign exchange market. The practical implication of these findings is that it raises a policy concerns for the regulators of interbank foreign exchange transaction because the finding of this study signals liquidity squeeze in the market and it is a disincentive to international investors and market players. This is not unconnected to trend seeking and round tripping behavior.
\end{abstract}

Keyword: Exchange rate, volatility, Economy, TGARCH, asymmetry, monetary policy

\section{Introduction}

Today, exchange rate volatility has expanded research horizon in the developing economies due to persistent exchange rate fluctuations. In reality, exchange rate volatility measures the degree of variation of the current spot price from its average past values, which is synonymous with risk level of the foreign market (Atoi, 2014). No doubt, exchange rate risk is better analyzed in terms of volatility. The risk aptitude is represented by the extent of dispersion of returns around the mean. Essentially, exchange rate volatility depicts the magnitude of rising and falling of domestic currencies with respect to another. This implies that the performance of currency market in terms returns gets better as volatility tends to decline; and plummets as volatility tends to rise. Thus, there is no gain saying that the fluctuations of exchange rate in Nigeria have remained a worrisome reality that requires persistent research consideration due to the following logical reasons. First; exchange rate plays important roles in the monetary policy transmission mechanism in any economy. In fact, regulators of the key players in the foreign exchange market are greatly concerned about exchange rate fluctuation risk because persistent exchange rate volatility causes loss of investors' confidence thereby reducing market participation and liquidity and price instability. Second; it aids the achievement of financial system stability in liberalized economies. Third; the fluctuations of exchange rate within a tolerable risk limit no doubt preserve external reserves to secure the external value of local currency. Exchange rate risk also emanate from internal imbalance that could result to decline in the foreign reserves and heightened pressure on demand for foreign exchange. Additionally, exchange rates of most economies, and specifically, the emerging economies' currencies, often deviate from the expected path due to emerging economies' exposure to changes in the fundamentals of their major trading partners; resulting to exchange rate risk transfer to other sectors of the local economy.

Traditionally, since post Structural Adjustment Prpgramme(SAP) era and after the liberalization of segments of Nigerian economy, the flexible exchange regime was adopted which provides the framework for determining exchange rate that facilitate transactions in foreign currencies. Until the new foreign exchange regime was introduced in June 2016, which further liberalized the market, different foreign exchange were quoted. At different regime periods, the currency market faced some challenges as the prevailing naira to USD exchange rates ( $\$ /$ US $\$$ ) in the three segments of the market witnessed some degrees of volatility. These three segments of the market include: Inter-bank Foreign Exchange Market (IFEM), Bureau de Change (BDC) and Wholesale Dutch Auction System (WDAS). The Nigerian Commercial banks, Bureau de Change, and Central Bank of Nigeria have been the main players in the foreign exchange market in Nigeria. 
Although, ample research have been documented on exchange rate in the apparent literature; but there is a hand full of reasons for further research on the subject matter of exchange rate volatility in the Nigerian emerging economy. First, the Nigerian foreign exchange market has witnessed significant demand pressure and speculative attack by market participants which led to volatility in exchange rates in the three segments of the market. For example, throughout 2010 to the fourth quarter of 2013, the three segments of the Nigerian foreign exchange market faced increased volatility. The continued demand pressure in the late 2014 has led to wide divergence between the official and the BDC rates. The naira depreciated by 5.7 per cent in December, 2014, while BDC premium widened to 11.1 per cent, thereby encouraging rent seeking and aggravated speculative attack. Second, the dwindling oil prices in the international market have challenged the ability of the central bank to accumulate reserves and defend the local currency. This calls for a robust volatility model capable of reassessing persistence of the risks in foreign exchange transactions. Third, the current persistent exchange rate fluctuations in Nigeria as well as the level of uncertainties in the Inter-bank Foreign Exchange Market, bureau de change, and Wholesale Dutch Auction System have been observed over time and the level of persistence visà-vis the asymmetric effect need to be appropriately documented in the extant literature. Fourth, studies have attempted to model exchange rate behavior on the framework of earlier theories like the law of one price and purchasing power parity. For the fact that these theories focused on goods markets rather than asset market and did not emphasize the changing expectations as a source of volatility, they fail to predict substantial fluctuations in exchange. Critics have also queried, with strong reasons, the use of first moment in modeling exchange rate volatility. For instance, Basurto and Ghosh (2001) note that simple time series correlations or vector autoregressions captures very little properties of exchange rate behavior, and their empirical performance in explaining their movements is limited. The failure of earlier models to adequately capture exchange rate behavior and its statistical properties necessitates the use of asymmetric conditional volatility model that adequately estimate changes in the exchange rate. There is a general consensus among researchers that shortterm variability of assets prices are better captured by linearly unpredictable stochastic processes that are unconditionally leptokurtic and conditionally heteroskedastic (Domowitz and Hakkio, 1985; Diebold,1988). Similarly, an adequate volatility model must sufficiently models heteroscadasticity in the disturbance term and also captures the stylized fact inherent in return series such as volatility clustering, Autoregressive Conditional Heteroscadasticity (ARCH) effect and asymmetry (Engel; 1982).

Additionally, as much as can be established in the discernible literature, the use of simple univariate GARCH type models, Glosten et al (1993), in the study of exchange rate volatility is scanty in Nigeria, except for Olowe (2009), Babatunde and Akinwande (2013) and Isenahand Olubusoye (2016); even when anecdotal evidence has shown that univariate volatility models are robust in capturing the main stylized facts in financial time series. Beside, none of them considered the three segments of the foreign exchange market. The consideration of these market segments is particularly important in view of the fact that the same policy measures may not address issues of volatility in the these markets. Also, available literature in Nigeria oftentimes ignored the contribution of error distribution in the estimation of exchange rate volatility models, notwithstanding the implications on the parameter estimates. According to Atoi (2014), the application of inappropriate error distribution in a volatility model for financial time series could engender mis-specification because of the leptokurtic and autocorrelation characteristics of such series. Therefore, this study is motivated to use the asymmetric volatility approach to model the volatility of naira to USDollar exchange rates with the view to establishing the level of volatility persistence and presence of asymmetric effect on the three segment of the Nigerian foreign exchange market. The rest of this paper is organized as follows; Section twopresents the exchange rate developments, theoretical and empirical Literature. Section three describes the methodology and the data. Section four presents the empirical results and section five concludes the study.

\subsection{Trends of Exchange Rate fluctuations in Nigeria}

\section{Conceptual And Theoretical Review}

Exchange rate of the naira to the US dollar was relatively stable in 2010. On average, the naira traded at N150.30 per US dollar at the WDAS segment of the foreign exchange market in 2010, recording a depreciation of 0.9 per cent when compared with the level in 2009. The rate was more volatile in 2011. The naira that traded at N150.48 to US dollar in December 2010 was N158.21 December 2011 at the WDAS segment of the foreign exchange market. Throughout 2012 and in most part of 2013, the foreign exchange market remained relatively stable as the market premium was within the international threshold of 5.0 per cent. Despite the robustness of the external sector in 2013, it however was susceptible to external shocks due to the continued exposure of huge inflow of short-term capital and non-diversification of the economy. Within the first half of 2016, the average exchange rates at the interbank and BDC segments depreciated by 15.00 and 26.58 per cent, respectively. The monetary authority has consistently issued guidelines on exchange rate to ensuring a stable foreign exchange rate which was sustained throughout 2015 and into the first half of 2016. The most recent is the introduction of flexible exchange rate regime. The objective of the policy was to enhance 
efficiency, boost liquidity and promote financial security in the market. The new exchange rate regime provides the platform for a single market mechanism using a two-way quote trading system. These include; foreign exchange primary dealers (FXPDs) approved by the CBN to transact among themselves, with CBN and NonFXPDs. Also, through the Secondary Market Intervention Sales (SMIS), CBN intervene by dealing directly with end users through their banks. Notwithstanding, internal and external shocks have challenged efforts to lower exchange rate volatility

\subsection{Theoretical Framework}

Purchasing Power Parity

One of the most prominent theories for examining exchange rates behavior is the purchasing power parity (PPP). It states that exchange rates between any two currencies will adjust to reflect changes in the price levels of the two countries. In other words, the PPP exchange rate advocates that the same basket of goods should costs the same in each country once allowance is made for different currencies. The theory of PPP is simply an application of the 'law of one price,' which stipulates that the identical commodities should sell at the same price wherever they are sold. PPP also explain the behavior of exchange rate through the concept of 'real exchange rate.' The key factors that determine the real exchange rate are volatile, causing the volatility in the real exchange rate that leads to a volatile nominal exchange rate. By and large, the PPP theory cannot fully explain exchange rate behavior due to the assumption that all goods are identical in any two countries under consideration and that the transportation costs as well as trade barrier are very low. These assumptions are unrealistic considering the variation in qualities of the goods produced in the two countries. Furthermore, PPP theory does not take into account goods and services whose prices are not included in a measure of country's price level and are not traded across borders, hence the adoption of second theory-Interest Parity Condition. Additionally, for proper theoretical understanding of changes in exchange rates, the interest parity condition (IPC) theory aptly shows the relationship between domestic interest, foreign interest rate and expected appreciation of the domestic currency. The IPC states that the domestic interest rate equals the foreign interest minus the expected appreciation of the domestic currency. In algebraic terms, IPC is represented as:

$$
i^{D}=i^{F}-\frac{E_{t+1}^{e}-E_{t}}{E_{t}}---------------(1)
$$

Where $i^{D}$ is the domestic interest rate, $i^{F}$ is the foreign interest rate, $E_{t+1}^{e}$ is the expected domestic currency at time $t+1$ and $E_{t}$ is the actual domestic currency at time $t$. On the other hand, IPC is expressed as

$$
E_{t}=\frac{E_{t+1}^{e}}{i^{F}-i^{D}+1}-----------------(2)
$$

\subsection{Review of Threshold Empirical Literature}

Empirical literature on the volatility of financial assets have been enlarged, most of which applied simple univariate GARCH and its extensions.Bollerslev (1987), Hsieh (1989) and Andersen and Bollerslev (1998). The application of this category of GARCH models is to confirm the stylized facts in financial returns. For instance, Luguterah et al (2015) examine the Ghana Cedi-United States Dollar exchange rate volatility in Ghana by applying monthly exchange rate returns from January 1990 to November 2013 on symmetric and asymmetric GARCH models. The result of the study revealed persistence of volatility and the non-existence of leverage effects as shown by the asymmetric models. The implication of the result is that information about asymmetry in the Ghana foreign exchange market may not have been necessary for investors who hedged against future exchange rate risk during the period of analysis. In a like manner, Rofael and Hosni (2015) modeled the volatility of exchange rate in Egypt using ARCH type models and the State Space (SS) models with daily exchange rate data spanning from January 2003 to June 2013. The result shows that exchange rate returns exhibit volatility clustering phenomenon and existence of time-varying variance in the exchange rate series that has to be accounted for when modeling nominal exchange rates. The established volatility clustering phenomenon in this work is one of the key characteristics of financial returns series, indicating that sustained period of relative calmness is followed by sustained period of high volatility in the Egyptian exchange rate market during the sample period. Moreover, Engle and Patton (2001) opine that such volatility clustering implies that current volatility shocks will influence the expectation of volatility many periods in the future.

Furthermore, the existence time-varying variance in the exchange rate series implies that the use of econometric model that assumes constant variance or Gaussian process of the disturbances. This fact is supported by the established evidence of Malmsten and Terasvirta (2004) that the assumption of normal errors in a time varying volatility model is not sufficiently flexible enough for capturing kurtosis and autocorrelation in stock returns. Pacelli (2012) employed the Artificial Neural Networks (ANN), ARCH and GARCH models to forecast the Euro/USdollar daily exchange rate. The ARCH and GARCH models were found according to the interpretation of the study, to be better than the ANN for the purpose of analyzing and forecasting the dynamics of the exchange rates in the country. The inference from the study is supported by Tambakis and Van-Royen, 
(2002) and Isenah and Olubusoye (2016), that univariate ARCH/GARCH models have tremendous successes in modeling second-order moments of financial and economic time series. In contrary, Deniz, and Akkoc (2013) and Charef and Ayachi (2016) found that neural network model remains the most performed forecasting model when compared with heteroscedastic models. This controversy exists if attention is on prediction; but when focus is on the stylized facts of financial returns, heteroscedastic models appears more appropriate because ANN does not clearly elucidate the stylized dynamics in assets returns. By use of GARCH, TARCH and EGARCH models to test the hypothesis of asymmetry and leverage effect in the exchange rate return of Korea, Yoon and Lee (2008) conclude that TARCH and EGARCH fit better indicate the existence of asymmetry and leverage effect in the Korean currency. Similarly, Pelinescu (2014) analyzed the volatility of the leu/euro exchange rate in Romania, taken into account the influence of the volatility of other currencies and other fundamental macroeconomic variables (January 2000 to August 2013). By application of different ARCHGARCH they confirmed a high asymmetry in the evaluation of information regarding the evolution of the exchange rate. While it looks like the stylized facts appears to be evident in all economies, Sandoval (2006), uses daily sample from 2000 to 2004 for In seven countries of Asia and Latin America Sandoval (2006) while applying the traditional GARCH, GJR-GARCH and EGARCH report that with the aid of Akaike and Schwartz criteria, four of the seven currencies were asymmetric. The symmetric model was found to possess more prediction than the asymmetric ones within the forecast horizon. The implication of this finding is that not all emerging economies' exchange rates exhibit widespread evidence of asymmetry.

Empirical literature on the use of simple univariate GARCH type models in exchange rate volatility is scanty in Nigeria.See Olowe (2009), Awogbemi and Alagbe (2011), Babatunde and Akinwande (2013) and Isenah and Olubusoye (2016). For instance, Olowe (2009) employed first order symmetric and asymmetric models using monthly data from January 1970 to December 2007 to investigate the volatility of Naira/Dollar exchange rates in Nigeria by separating the volatility of during fixed exchange rate from the managed float regime. The results from all the models show that volatility is persistent; all asymmetric models rejected the hypothesis of leverage effect for the two regimes. The result is the same for the fixed exchange rate period and managed float rate regime. The TSGARCH and APARCH models are found to be the best models. Though the same TSGARCH is used in our study, but Olowe's paper is significantly different from ours in the area of data frequency, exchange rate regime and segment of market being considered. Again, Babatunde and Akinwande (2013) examined the consistency, persistency, and severity of volatility in exchange rate of Nigerian currency vis-a-vis the United States dollar using monthly time series data from 1986 to 2008 . The PPP model was used to analyze the long-run consistency. The result indicates that the nominal and real exchange rates of naira vis-a-viz the U.S dollar is not consistent with the traditional long-run PPP model. The authors accept the inability of symmetric GARCH model to fully account for the stylized facts, such as leverage effect and inherent in financial time series and called for further study that will address this limitation. The volatility of Naira/US Dollar and Naira/UK Pound Sterling exchange rates in Nigeria was estimated by Awogbemi and Alagbe (2011) with symmetric GARCH model. Results showed that volatility on the returns is persistent. Due the limitation of their study, the level of persistence arising from their study may be inaccurate, and these gaps is what our study seeks address.

\subsection{Estimation Procedures}

\section{Methodology}

The estimation procedure starts with generation of exchange rate returns, which are subjected to unit root test because the important test statistics used in the evaluation of the econometric results become unreliable if the series is not stationary. We establish the appropriateness of the multivariate GARCH models in the study by conducting an ARCH-effects test of Engle (1982), which is complemented with correlogram test of squared returns. Having confirmed the ARCH-effects presence, the asymmetric conditional volatility model was estimated alongside their mean equation using maximum likelihood method. It is widely accepted that return series do not follow normal distribution; hence the models were estimated under student's $t$ assumption and generalized error distribution (GED) since they account for fat tail. In a risk management context, assuming normality when returns are fat-tailed will result in a systemic underestimation of the riskiness of the portfolio (Brooks, 2013). The robustness of the estimated models is evaluated using standard model evaluation criteria - Schwartz Bayesian Criterion (SIC) and Akaike Information Criterion (AIC). Again, ARCH-Effect test is conducted to know if it has been accounted for by the model.

\subsection{Data and Variables}

In this study, the three segments of the Nigeria Foreign Exchange Market, namely Bureau de Change (BDC), Inter-bank Foreign Exchange Market (IBFEM) and Wholesale Dutch Auction System (WDAS) were duly captured. The data used in the study covered the daily DBC, Interbank and WDAS nominal exchange rates (A/US\$) from January 4, 2010 to February 18, 2015, totaling 1,262 observations. The data were obtained from the CBN website (www.cenbank.org). Since the model does not account for structural changes, the sample period was systematically chosen to avoid biases that could arise from major structural shift that occurred before 
and after the sample period, such as the global financial crisis and oil shocks in Nigeria. The daily exchange rate data in the three segments of the market were transformed to daily exchange rate returns, $y_{t}$, expressed as:

$$
y_{t}=100 \ln \left(X_{t} / X_{t-1}\right)------------(3)
$$

Where $X_{t}$ is the current period spot exchange rate, $Z_{t-1}$ is the preceding period spot exchange rate, and $y_{t}$ is the current period spot exchange rate returns (X-RT). The existence of volatility clustering in $y_{t}$ is established by plotting the residuals of the equation:

$$
y_{t}=\Gamma+\xi_{t}---------------(4)
$$

Гis a constantand $\xi_{\mathrm{t}}$ is the residual series. The null hypothesis that there is no ARCH in the residuals is tested using the Lagrange Multiplier (LM) test up to order 10 at 5\% significance level. The presence of ARCH effect is a precondition for GARCH modeling, which serves as an antidote for ARCH effect in a financial series.

3.3 Model Specification

The asymmetric Threshold Generalized Autoregressive Conditional Heteroscadasticity model (TGARCH) proposed by Glosten et al (1993) is estimated. This requires the simultaneous estimation of the mean and conditional variance equations. The mean equation is specified as:

Such that $\varepsilon_{t}=\varphi_{t} \sigma_{t}$

$$
y_{t}=E_{t-1}\left(y_{t}\right)+\varepsilon_{t}-----------(5)
$$

$E_{t-1}[$.$] is expectation conditional on information available at time t-1, \varepsilon_{t}$ is error generated from the mean equation at time $t$ and $\varphi_{t}$ is a sequence of independent, identically distributed (iid) random variables with zero mean and unit variance. $E\left\{\varepsilon_{t} / \Omega_{t-1}\right\}=0$; and $\sigma_{t}^{2}=E\left\{\varepsilon_{t}^{2} / \Omega_{t-1}\right\}$ is a nontrivial positive-valued parametric function of $\Omega_{t-1}$.

The conditional variance equation is specified as:

Where $I_{t-1}=1$ if $\varepsilon_{t}^{2}<0$ and 0 otherwise.

$$
\sigma_{t}^{2}=\beta_{0}+\alpha_{1} \varepsilon_{t-1}^{2}+\gamma_{1} I_{t-1} \varepsilon_{t-1}^{2}+\beta_{1} \sigma_{t-1}^{2}----(6)
$$

In this model, good news implies that $\varepsilon_{t-1}^{2}>0$ and bad news implies that $\varepsilon_{t-1}^{2}<0$; and these two shocks of equal size have differential effects on the conditional variance. Good news have an impact of $\alpha_{1}$ and bad news have an impact of $\alpha_{1}+\gamma_{1}$. Bad news increase volatility when $\gamma_{1}>0$, which implies the existence of leverage effect in the 1 st order and when $\gamma_{1} \neq 0$ the news impact is asymmetric.

3.4 Innovation Process

The error from the mean equation is allowed to follow student's $t$ distribution $(t)$ and generalized error distribution (GED) since normality assumption has demonstrated some levels of weaknesses in volatility modeling. The contribution of GED to the asymmetric TGARCH model is expressed by its log likelihood below:

$$
L\left(\theta_{t}\right)=-\frac{1}{2} \log \left(\frac{\Gamma 1 / v^{3}}{\Gamma(3 / v)(v / 2)^{2}}\right)-\frac{1}{2} \log \sigma_{t}^{2}-\left(\frac{\Gamma(3 / v)\left(y_{t}-X_{t}^{\prime} \theta\right)^{2}}{\sigma_{t}^{2} \Gamma(1 / v)}\right)^{v / 2}---(7)
$$

$v>0$ and it accounts for the skewness of the returns. The higher the value of $v$, the greater the weight of tail. GED reverts to normal distribution if $\mathrm{v}=0$

For Student's t distribution, the log likelihood contributions to the two models are expressed as:

$L(\theta)_{t}=-\frac{1}{2} \log \left(\frac{\pi(r) \Gamma r / 2^{2}}{\Gamma((r+1) / 2)^{2}}\right)-\frac{1}{2} \log \sigma_{t}^{2}-\frac{(r+1)}{2} \log \left(1+\frac{\left(y_{t}-X_{t}^{\prime} \theta\right)^{2}}{\sigma_{t}^{2}(r-2)}\right)------(8)$

Here, $r$ is the degree of freedom and control the tail behaviour and $r>2$.

\section{Descriptive statistics}

\section{Results And Discussion}

The descriptive statistics in table $\mathbf{1}$ shows a common sample for the exchange rates. The positive mean values suggest more depreciation of the exchange rates than appreciation. The skewness indicate that BDC and ITB exchange rates have more positive distribution (skewed to the right), while the official (WDAS) exchange rate are negatively skewed. Also, the values of skewnes show that the three rates are asymmetric. The kurtosis values also suggest non-normality and likely presence of ARCH effect. The Jarque-Bera values and their corresponding small p-values provide further evidence that the series are non-Gaussian.

Table 1: Descriptive Statistics

\begin{tabular}{|l|l|l|l|}
\hline & BDCR & ITBR & WDASR \\
\hline Observations & 1261 & 1261 & 1261 \\
\hline Measures of Central Tendencies & 0.000219 & 0.000103 \\
\hline Mean & $\mathbf{0 . 0 0 0 2 5 9}$ & 0.000185 & 0.000000 \\
\hline Median & $\mathbf{0 . 0 0 0 0 0 0}$ & $\mathbf{0 . 1 5 3 9 3 7}$ & $\mathbf{0 . 0 2 5 4 9 1}$ \\
\hline Maximum & $\mathbf{0 . 0 6 5 1 8 6}$ & $\mathbf{- 0 . 1 3 9 7 2 9}$ & $\mathbf{- 0 . 0 4 5 0 3 7}$ \\
\hline Minimum & $\mathbf{- 0 . 0 3 5 0 9 1}$ & \\
\hline Measures of Dispersion
\end{tabular}




\begin{tabular}{|l|l|l|l|}
\hline Std. Dev. & 0.003691 & 0.008059 & 0.001889 \\
\hline Skewness & 8.443935 & 4.648334 & -7.198039 \\
\hline Kurtosis & 89.27383 & 181.8965 & 300.6794 \\
\hline Measures of Normality & 393569.5 & 1682112 & 4666766 \\
\hline Jarque-Bera & 0.00000 & 0.00000 & 0.00000 \\
\hline Probability
\end{tabular}

Source: E-view

4.1 Graphical Analysis of Naira exchange rate to US dollar Exchange Rates in the three Market Segments Inspection of exchange rate returns graphs indicates mean reversion of the series, that is, deviation from the mean is not permanent. Mean reversion is a stylized fact of financial assets. Also, the exchange rate returns exhibit clustering behavior as sustained period of calmness is followed by another sustained of period of uncertainties. Clustering is another stylized fact of financial time series like exchange rate. The revelation of basic stylized facts provides justification for the application of asymmetric conditional volatility models (TGARCH).

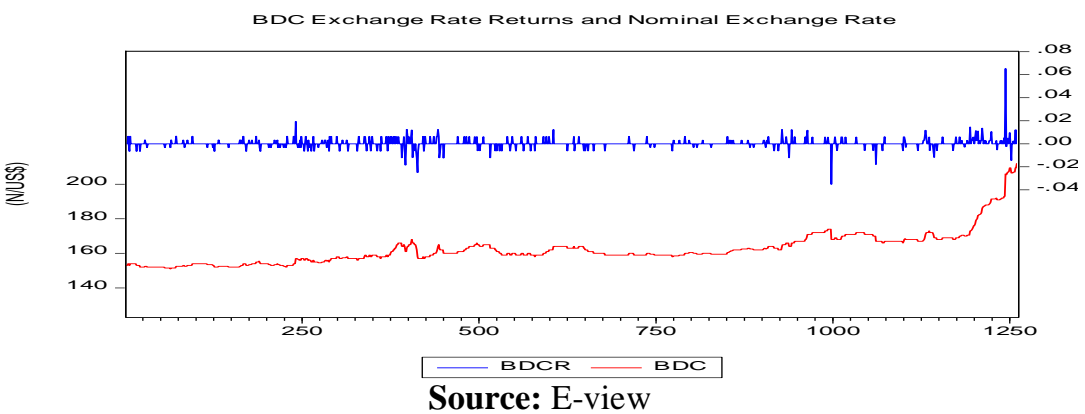

A close inspection of the plots reveals that the interbank exchange rateis marginally more volatile than the $\mathrm{BDC}$ exchange rate. The reason may not be unconnected to the closer monitoring of the bank's foreign exchange transactions by the CBN and lose supervision of the BDC. The high volatility of the interbank foreign exchange market also suggests that the market is less liquid than the BDC segment, because the more liquid a market is, the higher the confidence and the lower the liquidity. But in practice, it is obvious that the interbank market is more funded, and expected to be more liquid.

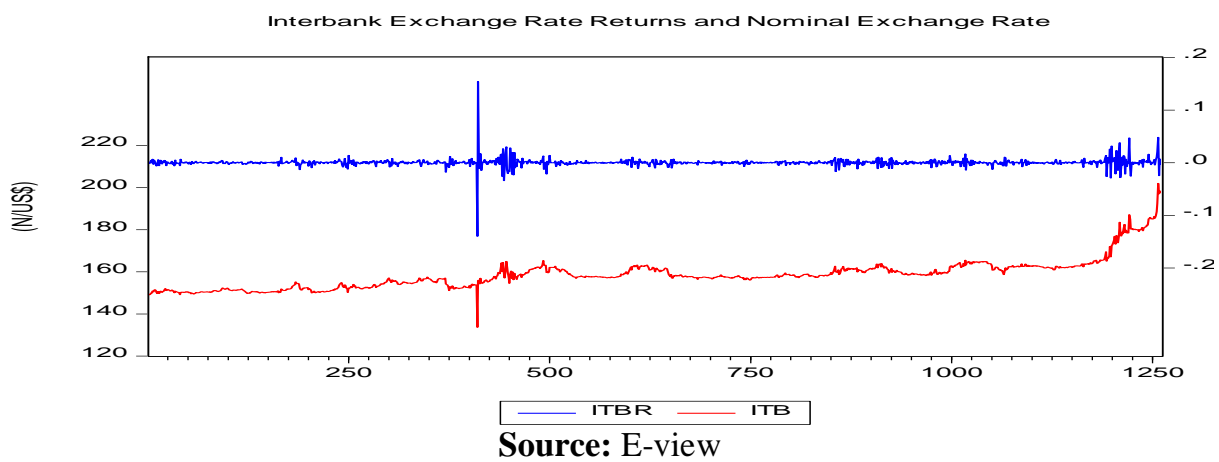

The plot indicates that average Naira exchange rate vis-à-vis the US dollar in interbank and BDC markets seem to be more volatile than the official exchange rate. This is supported by the upward trend of the nominal exchange rate, while the official exchange rate was relatively stable over a long period.

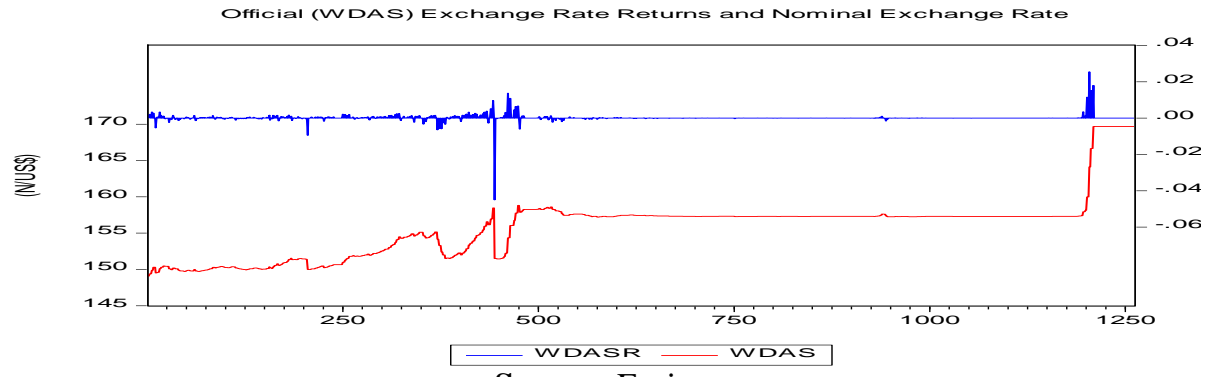

Source: E-view 


\subsection{Unit Root Test}

The Naira to US dollar exchange rates returns in the three markets segment were tested to determine their stationarity. As expected for return series, the unit root test results in table 2 reveal that the returns series are stationary at all conventional levels of significance considering the small values ADF-test Statistic.

Table 2: Unit Root Test Results

\begin{tabular}{|l|l|l|l|}
\hline & BDCR & ITBR & WDASR \\
\hline ADF-test & -33.47142 & -24.59047 & -11.95244 \\
\hline t-Statistic & -3.435327 & -3.43534 & -3.435344 \\
\hline $1 \%$ level & -2.863626 & -2.863631 & -2.863633 \\
\hline $5 \%$ level & -2.56793 & -2.567933 & -2.567934 \\
\hline $10 \%$ level &
\end{tabular}

Source: E-view

\subsection{Post Estimation Analysis and Model Selection}

The information criteria obtained from estimated results of Naira to US dollar exchange rates returns in the three segments of the foreign exchange market using asymmetric Threshold Generalized Autoregressive Conditional Heteroscadasticity model (TGARCH), under student's-t and GED error assumptions is reported in table 3. Akaike info criterion and Schwarz criterion are consistent in determining the appropriate distribution. The volatility model under student's-t error is suitable for modeling Naira to US dollar exchange rates of interbank, while conditional variance model under GED was suitable for modeling Naira to US dollar exchange rate of WDAS and BDC.

Table 3:Information Criteria

\begin{tabular}{|l|l|l|l|l|l|l|}
\hline & \multicolumn{3}{|l|}{ Akaike info criterion } & \multicolumn{2}{c|}{ Schwarz criterion } \\
\cline { 2 - 7 } & Student-t & GED & Minimum & Student-t & GED & Minimum \\
\hline BDCR & $\mathbf{- 1 4 . 0 5 8 9}$ & $\mathbf{- 1 1 6 . 4 0 9 9}$ & $-\mathbf{1 1 6 . 4 0 9 9}$ & $-\mathbf{1 4 . 0 3 4 4}$ & $\mathbf{- 1 1 6 . 3 8 5 4}$ & $\mathbf{- 1 1 6 . 3 8 5 4}$ \\
\hline ITDR & $\mathbf{- 8 . 6 3 8 8}$ & $\mathbf{- 8 . 5 8 0 2}$ & $\mathbf{- 8 . 6 3 8 8}$ & $\mathbf{- 8 . 6 1 0 3}$ & $\mathbf{- 8 . 5 5 1 7}$ & $\mathbf{- 8 . 6 1 0 3}$ \\
\hline WDAS & $\mathbf{- 1 0 . 4 4 4 2}$ & $\mathbf{- 1 0 9 . 0 2 8 6}$ & $-\mathbf{- 1 0 9 . 0 2 8 6}$ & $\mathbf{- 1 0 . 4 1 9 7}$ & $-\mathbf{1 0 9 . 0 0 4 2}$ & $\mathbf{- 1 0 9 . 0 0 4 2}$ \\
\hline
\end{tabular}

\subsection{Diagnostic Test of the Selected Volatility Models}

Before analyzing the parameters of the selected models, statistical tests were conducted to ascertain their robustness and consistencies to statistical theories. The presence of ARCH effect and serial correlation in the residual of the mean equation (standardized residual) reduces the efficiency of the conditional variance model.The test result for standardized residuals is shown in the table 4. From the values of Q-Statisticsand their corresponding probability values in the two tests (tables 4 and 5), the null hypotheses that "there is no serial correlation" cannot be rejected, suggesting the absence of serial correlation in the residuals, which gives credence to the conditional variance model applied. However, this is not the case for the WDAS exchange rate volatility model beyond lag 1 .More so, the result of Heteroscadasticity conducted is reported in the table 5 .

Given the high values of probabilities in the post ARCH test and the small values of F-Statistic, there is sufficient evidence that the null hypotheses that "there is no ARCH effect" cannot be rejected and we conclude that there is no remaining ARCH in the residuals.

\subsection{Analysis of Parameter Estimates}

The estimated parameters in the mean and variance equations for the best selected models are presented in the table 6.

Table 6: Estimated Volatility Models of Exchange Rates

\begin{tabular}{|c|c|c|c|}
\hline & BDR & ITDR & WDAR \\
\hline & \multicolumn{3}{|c|}{ Mean Equation } \\
\hline Constant & NS & $\begin{array}{l}0.00013 \\
(0.0025)\end{array}$ & NS \\
\hline \multirow[t]{2}{*}{$\mathbf{A R}(1)$} & $\begin{array}{l}-0.00051 \\
(0.0000)\end{array}$ & $\begin{array}{l}-0.14358 \\
(0.0000)\end{array}$ & $\begin{array}{l}-0.00026 \\
(0.0000)\end{array}$ \\
\hline & \multicolumn{3}{|c|}{ Variance Equation } \\
\hline Constant & $\begin{array}{l}0.00001 \\
(\mathbf{0 . 0 0 3 8}) \\
\end{array}$ & $\begin{array}{l}\mathbf{0 . 0 0 0 0 0 1} \\
(0.0000)\end{array}$ & $\begin{array}{l}0.00002 \\
(0.0104) \\
\end{array}$ \\
\hline Squared Residual & $\begin{array}{l}0.05066 \\
(0.0362)\end{array}$ & $\begin{array}{l}0.86811 \\
(0.0000)\end{array}$ & $\begin{array}{l}0.02646 \\
(0.1928)\end{array}$ \\
\hline Asymmetric Parameter & $\begin{array}{l}-0.05283 \\
(0.0315)\end{array}$ & $\begin{array}{c}-0.32730 \\
(0.0514)\end{array}$ & $\begin{array}{c}-0.10187 \\
(0.4133)\end{array}$ \\
\hline Lagged Variance & $\begin{array}{l}0.54381 \\
(0.0000)\end{array}$ & $\begin{array}{l}0.52716 \\
(0.0000)\end{array}$ & $\begin{array}{l}0.49497 \\
(0.0040)\end{array}$ \\
\hline Volatility Persistence & 0.59447 & 1.39527 & 0.52143 \\
\hline
\end{tabular}


Asymmetric Analysis of Exchange Rates Volatility: Evidence from Emerging Economy

\begin{tabular}{|l|l|l|l|}
\hline & Diagnostics \\
\hline ERROR-DIST. DOF & $\begin{array}{l}\mathbf{0 . 0 1 7 4 8} \\
(\mathbf{0 . 0 0 0 0})\end{array}$ & $\begin{array}{l}\mathbf{3 . 0 7 9 2 1} \\
(\mathbf{0 . 0 0 0 0})\end{array}$ & $\begin{array}{l}\mathbf{0 . 0 1 7 4 8} \\
(\mathbf{0 . 0 0 0 0})\end{array}$ \\
\hline Log likelihood & $\mathbf{7 3 3 4 4 . 2 4}$ & $\mathbf{5 4 4 9 . 4 5}$ & $\mathbf{6 8 6 9 4 . 0 3}$ \\
\hline Durbin-Watson stat & $\mathbf{1 . 8 7 4 0}$ & $\mathbf{2 . 5 4 8 4}$ & $\mathbf{1 . 9 9 9 9}$ \\
\hline Note: NS means NOT SIGNIFICANT. Numbers in brackets are probability values \\
\hline
\end{tabular}

Source: E-view

Autoregressive parameters of the mean equations of the Naira to US Dollar exchange rates in the three segment of the Nigeria foreign exchange market are highly significant at $1 \%$ level, indicating unbiasness of the unconditional variance. Only the intercept for interbank Naira to US Dollar exchange rate was significant. From the variance equation, the market shocks of the previous period has significant impact on the current volatility of both the interbank and BDC market segments as their parameter estimates, 0.051 for BDC and 0.868 for Interbank are significant at $5 \%$ and $1 \%$, respectively. However, the previous period market shock has more impact on current volatility of interbank Naira to US Dollar exchange rate. Contrary to these findings, the current volatility of WDAS exchange rate is not sensitive to past shock from the market. The non-significant impact of previous period foreign exchange market shock in the official segment is an indication of imperfection of market forces in exchange rate determination at the official window.

The impact of previous period volatilities on the current are highly significant in the three segments of the foreign exchange market. The magnitudes of impact are $0.544,0.527$ and 0.495 for BDC, Interbank and WDAS segments of the market. Consequently, volatility persistence which measures the time it takes for volatility in any of the market segment to dissipate or decay is given as the sum of parameter estimates of the past residuals and volatility in the conditional variance model. The estimated volatility models indicate that interbank market, BDC and WDAS Naira to US Dollar exchange rates are highly persistent/explosive (greater than 1), high (less than 1) and moderate (0.5), respectively. This result confirms the initial findings from exchange rates returns plots of the three segments.

Further, the result shows the presence of asymmetry or leverage effect in the interbank and BDC segments of the Nigeria foreign exchange market over the sample period as evidenced from the negative and statistical significance of their asymmetric parameters in table 6. In other words, it suggests that equal magnitude of positive and negative shocks have unequal effect on the conditional volatilities in the two market segments. Asymmetric information is critical to investment analysis for investment decision. However, this is not the case for the WDAS segment foreign exchange market.

\section{Conclusion And Policy Recommendations}

The study modeled the naira to US dollar nominal exchange rate volatility in the three segments of the Nigeria foreign exchange market using the asymmetric volatility model with 1,262 sample observations, from January 4, 2010 to February 18, 2015. The main objective is to determine the existence of stylized facts in the naira to US dollar nominal exchange rate, with particular reference to asymmetry and volatility persistence. In line with research objective, the results of the study were quite revealing. The naira to US dollar nominal exchange rate volatilities was found to be persistent in all the market segments. It is important to mention that the exchange rate volatility in the interbank is persistent and explosive; while the volatilities in the BDC and WDAS market are high and moderate, respectively. This raises a policy concerns for the regulators of interbank foreign exchange transaction because the results signals liquidity squeeze in the market and could be a deterrent to international investors and market players. The evidence shown in this study that the BDC segment of foreign exchange being less volatile than the interbank market segment calls for concern, knowing full well that interbank is more funded with foreign exchange both from autonomous and official sources. This may not be unconnected to rent seeking and round tripping behavior of the market. Furthermore, it is evident from this study that interbank foreign segment reacts more to past shocks of the foreign exchange market. The study also confirms existence of asymmetric or leverage effect in the foreign exchange market. The knowledge of asymmetry that equal magnitude of positive shocks and negative shocks has unequal effect on the conditional volatilities and helps investors to make well informed investment decision.

By way of recommendation, the monetary authority should expand their supervisory and monitoring tools to ensure that rent-seeking behavior does not exist in the interbank segment of the foreign exchange market. This can be done by ensuring that foreign exchange allocated to interbank players get to the end-users. Foreign exchange market infrastructure should be enhanced, especially in the area of information and communication technology to reduce the level of uncertainty found in the interbank foreign exchange market in Nigeria.

\section{Limitation Of The Study}

The inability to apply volatility model that account for regime shift in order to increase the period covered. 


\section{References}

[1]. Adeoye, B. W. and Atanda, A. A. (2012), Exchange rate volatility in Nigeria: consistency, persistency and severity analysis. CBN Journal of Applied Statistics, 2(2), 29-49.

[2]. Andersen, T. and Bollerslev, T. (1998), Answering the skeptics: yes, standard volatility models do provide accurate forecasts. International Economic Review, 39, 885-906

[3]. Atoi, N. V. (2014), Testing Volatility in Nigeria Stock Market using GARCH Models. Central Bank of Nigeria Journal of Applied Statistics, 5(2)

[4]. Awogbemi, C. and Alagbe, S. (2011), Empirical Modeling of Nigerian Exchange Rate Volatility. Mathematical Theory and Modeling ISSN 2224-5804

[5]. Babatunde, W. A. and Akinwande A. A. (2013), Exchange Rate Volatility in Nigeria: Consistency, Persistency \& Severity Analyses. CBNJournal of Applied Statistics, 2 (2)

[6]. Baillie, R. T., Bollerslev, T. and Mikkelsen, H. O. (1996), Fractionally integrated generalized autoregressive conditional heteroskedasticity J. Econometrics 74 3-30

[7]. Black, F. (1976), Studies of Stock Price Volatility Changes. Proceedings of the 1976 Meetings of the American Statistical Association, Business and Economic Statistics Section, 177-181.

[8]. Bollerslev, T. (1987), A conditionally heteroskedastic time series model for speculative prices and rates of returns. The Review of Economics and Statistics, 69, 542-547.

[9]. Chou, R. Y. (1988) Volatility persistence and stock valuations: some empirical evidence using GARCH J. Appl. Econometrics 3 279-94

[10]. Chow, H., Kwan, K. and Yoonbai (2004), The Empirical Relationship between Exchange Rates and Interest Rates in Post-Crisis Asia. Research Collection School Of Economics.

[11]. Deniz,Y. and Akkoc, S. (2013), A Comparison of Linear and Non Linear Models in Forecasting Market Risk: The Evidence from Turkish Derivative Exchange. Journal of Economics and Behavioral Studies, 5(3),pp.164-172

[12]. Diebold, F. X. (1986), Testing for Serial Correlation in the presence of Heteroskedasticity. Proceedings from the America Statistical Association, Business and Economics Statistics Section 323-328

[13]. Domowitz, I. and Hakkio, C. S. (1985), Conditional Variance and Risk Premium in the Foreign Exchange Market.Journal of International Economics 19: 47-66

[14]. Engle, R. F. (1982), Autoregressive Conditional Heteroskedasticitywith Estimates of the Variance of United Kingdom Inflation. Econometrica, 50. 987-1007.

[15]. Fahima, C. and Fethi, A. (2016), International Journal of Academic Research in Business and Social Sciences, 6,(1)

[16]. Gabriela, B. and Atish, G. (2001), The Interest Rate-Exchange Rate Nexus in Currency Crises. IMF Staff Papers, 47, Special Issue

[17]. Glosten, L. R., Jagannathan, R. and Runkle, D. E. (1993), On the Relation between the Expected Value and the Volatility of the Nominal Excess Return on Stocks.Journal of Finance, 48(5):1779-1801.

[18]. Hsieh, D. (1989). Modeling heteroscedasticity in daily foreign exchange rates. Journal of Business \& Economic Statistics, 7, 307317.

[19]. Isenah, G. M. and Olubusoye, O. E. (2016), Empirical Model for Forecasting Exchange Rate Dynamics: the GO-GARCH Approach. CBN Journal of Applied Statistics, 7,1(b)

[20]. Luguterah, A, Akumbobe, R.A. and Yaan, E. A. (2015), Modelling Exchange Rate Volatility of The Ghana Cedi to the Us Dollar Using GARCH Models. Mathematical Theory and Modeling ISSN 2224-5804,5(8),

[21]. Mlambo, C. M. and Andrew, S. K. (2013), Effects of Exchange Rate Volatility on the Stock Market: A Case Study of South Africa ,Mediterranean Journal of Social Sciences MCSER Publishing, Rome-Italy, 4 (14)

[22]. Olowe, R. A. (2009), Modelling Naira/Dollar Exchange Rate Volatility: Application of GARCH and Asymmetric Models. International Review of Business Research Papers, 5, (3)

[23]. Pacelli, V. (2012), Forecasting Exchange Rates: A Comparative Analysis. International Journal of Business and Social Science,145156

[24]. Pelinescu, E. (2014), Volatility analysis of the Romanian exchange rate. Procedia Economics and Finance 8543 - 549

[25]. Rofael, D. and Hosni, R. (2015), Modeling Exchange Rate Dynamics in Egypt: Observed and Unobserved Volatility. Modern Economy, 65-80.

[26]. Schwert, G. W. (1989), Why does stock market volatility change over time? J. Finance $441115-53$

[27]. Tambakis, D. N., Van-Royen A. (2002), Conditional Predictibility of Daily Exchange Rate, Journal of Forecasting,21,301-315

[28]. Yoon, S. and Lee K. S. (2008), The Volatility of Won/Dollar Exchange Rate. Journal of Social Science, 4(1), p.7-9 